\title{
Integrated thermomechanical model for forming of glass containers
}

\author{
Bruno Martins ${ }^{1, \text { a }}$, Ana Reis ${ }^{1}$, Pedro Teixeira ${ }^{1}$, Margarida Machado ${ }^{1}$, Jaime Rodrigues ${ }^{2}$ and J. Cesar de Sáa \\ ${ }^{1}$ INEGI, Institute of Science and Innovation in Mechanical and Industrial Engineering, 4200-465 Porto, Portugal \\ ${ }^{2}$ University of Porto, Mechanical Department, 4200-465 Porto, Portugal
}

\begin{abstract}
In this work an integrated model for all the process of glass forming of glass containers is presented. The model addresses press-and-blow and blow-and-blow procedures from the gob forming to the final product. Glass forming involves coupled thermal-mechanical physical phenomena, in which the material viscous flow is highly dependent on heat transfer which, in turn, is dependent changes of shape due to material flow. Numerical aspects associated with the model implementation and its validation with real formed products are discussed.
\end{abstract}

\section{Introduction}

The growth of competitiveness on the industries that use glass containers puts demands on the glass industry to develop new designs. In this context, simulations models are essential as virtual prototyping tools, reducing time and costs. To be effective, the model must give some information for the optimisation of the process, namely thickness evolution, residual stresses and mould temperatures distributions. The forming of hollow-ware glass articles is a complex coupled thermal/mechanical problem with interaction between the heat transfer analysis and the viscous flow of molten glass. The glass viscosity, which governs the glass flow during the forming process, is strongly dependent on the temperature [1-2] and the contact with the moulds along with the constant geometry changes alters significantly the heat transfer process. The final product thickness distribution is one of the aspects which is more affected by changing process conditions [2, 4-7].

Simulating glass forming with FEM is particularly difficult task since the material behaviour lies somewhere between a fluid and a solid. One of the first models was developed by Cesar de Sa [2]. In his approach, the thermal problem is coupled to the mechanical one at every time step, in order to handle the strong coupled phenomena. The model has provided good predictions of glass flow, resulting from gravity and blow pressure. The model was the basis for the development of a commercial 2D code [9]. But, nowadays, manufacturers are facing an evolving and increasing competition in the development of new complex 3D products. Tools are available which are capable of dealing with the most important aspects of these forming processes [10-11]. Nevertheless, some particular aspects requires a dedicated software or some user intervention in order to adapt commercial codes to this particular field (which may not be an easy task). Besides the referred commercial code, a new approach has been recently released, [12], based on meshless methods, with 3D modelling. Nevertheless, in those software some important features in terms of process knowledge still lack or are simplified like, for example, the plunger movement defined by a prescribed velocity, which does not represent the real case, where a pressure must be set. A software suite for glass forming should include the calculation of gob $^{1}$ initial geometry and temperature distribution, as well as moulds heat transfer with the glass and with external ambient temperature, in order to optimize the final geometry and process efficiency.

This last feature is not available in the mentioned software. Besides the paramount importance in the final container thickness distribution, it can be also extremely useful for machine developers since it allows to design dedicated cooling systems that could push the process further to its limits. Therefore the main objective is to build a robust and reliable suite of numerical modelling programs designed to provide glassmakers with decision support system tools to aid in the design, production and quality control of all types of glass containers. The programs should combine the latest numerical technology to provide practical, representative simulation tools that glassmakers can use and benefit from. They should be rooted in sound theoretical formulations to deal with the complex coupled thermal and mechanical phenomena, as glass viscosity is dramatically influenced by temperature distribution that itself is highly influenced by shape modification and contact with the tools and moulds. The suite of programs should also comprise pre and post processors and analysis modules for the complete definition of the problem, analysis and viewing of the results. It should be used to simulate the forming process

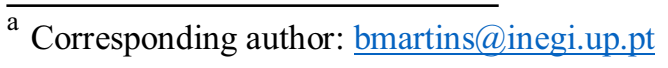


of round and non-round glass containers on an IS (individual section) forming machine from gob delivery through parison formation, invert and final blow until mould open.

The types of forming process modelled should include BB (Blow and Blow), PB (Wide Mouth Press and Blow) and NNPB (Narrow Neck Press and Blow) processes. As final result it should be possible to: predict the glass thickness distribution in the final product under a variety of conditions; analyse the thermal behaviour of the blank and blow moulds; investigate the influence of process conditions like glass composition, IS Machine timing, gob temperature, mould temperatures upon final container wall thickness results; evaluate the effects of mould cooling on the forming process and container wall thickness results. The final program should be not only a design tool for improvement and optimisation of existing products but also a means of understanding the main process parameters role to provide the assessment of new ideas for new products and innovation.

\section{Formulation problem}

\subsection{Constitutive model}

For the whole range of the forming process a nonlinear viscoelastic model, of a Maxwell type, is assumed for the constitutive behaviour of the glass, [13] and [14]. Therefore, assuming an additive decomposition of the strain rate tensor $\mathrm{D}$ in the elastic and the viscous strain rate tensors, $\mathbf{D}_{\mathbf{e}}$ and $\mathbf{D}_{\mathbf{v}}$ respectively, [15], and assuming that the viscous deformation is only deviatoric then:

$$
\begin{gathered}
\mathbf{D}=\mathbf{D}_{\mathbf{e}}+\mathbf{D}_{\mathbf{v}} \\
\mathbf{D}_{\mathbf{e}}=\frac{1}{3 \mathrm{~K}}\left[\frac{(\dot{\boldsymbol{\sigma}}: \mathbf{I})}{3}+\alpha \dot{\mathrm{T}}\right] \mathbf{I}+\frac{1}{2 \mu} \dot{\boldsymbol{\sigma}}^{\prime} \\
\mathbf{D}_{\mathbf{v}}=\frac{1}{2 \eta(\mathrm{T})} \boldsymbol{\sigma}^{\prime}
\end{gathered}
$$

where $\dot{\boldsymbol{\sigma}}$ and $\dot{\boldsymbol{\sigma}}$ 'are the time derivative of the stress tensor and of the stress deviator tensor, $\mathrm{K}$ and $\mu$ are the bulk and the shear elastic modulus, $\alpha$ is the coefficient of thermal expansion and $\eta(T)$ is the viscosity, dependent on the temperature $\mathrm{T}$.

The dependence of glass viscosity on the temperature is assumed to follow the relationship proposed by Fulcher, [16]:

$$
\log _{10} \eta(T)=A+\frac{B}{T-T_{0}}
$$

where $\mathrm{A}, \mathrm{B}$ and $\mathrm{T}_{\mathrm{o}}$ are empirical constants.

In the forming range of temperatures the elastic part of the deformation is almost negligible and therefore the constitutive behaviour is similar to the one of an incompressible Newtonian fluid. In the cooling stages after the containers are formed it is the viscous part of the deformation that is negligible and the constitutive behaviour is then mainly thermoelastic.

\subsection{Equilibrium equations}

The finite element model is established from the equilibrium equations for the thermo-viscoelastic problem. Neglecting inertia forces the mechanical equilibrium equations are:

$$
\operatorname{div}(\boldsymbol{\sigma})+\mathbf{b}=0
$$

where $\mathbf{b}$ are body forces per unit volume. In the forming range of temperatures, as referred, the deformation is almost incompressible, and, therefore, some care must be taken in the finite element model, when evaluating the volumetric terms, in order to avoid locking, [17]. The thermal equilibrium may be stated, for a Lagrangian set of coordinates, by the Fourier law, assuming that there is no heat source in the material, as:

$$
\mathrm{k}(\mathrm{T}) \nabla^{2} \mathrm{~T}=\rho(\mathrm{T}) \mathrm{c}(\mathrm{T}) \dot{\mathrm{T}}+3 \mathrm{~K} \alpha \mathrm{T}(\mathbf{D}: \mathbf{I})+\mathrm{r}\left(\dot{\boldsymbol{\sigma}}^{\prime}: \mathbf{D}\right)
$$

$\mathrm{k}$ is the thermal conductivity, $\mathrm{c}$ is the specific heat and $\rho$ is the density. The last term of the right hand side of equation [6] represents the fraction $r$ of viscous work that is converted into heat.

In the finite element solution the mesh representing the glass, is updated for each time step and therefore in the heat transfer equation [6] the convective terms were disregarded, i.e., the heat is convected each time step to the new mesh position, from where a diffusion process takes place. In the moulds the last two terms of equation [6] are not considered. The thermal natural boundary conditions may include a flux due to convection of the contact fluid, air in this case:

$$
\mathrm{q}_{\mathrm{c}}=-\alpha_{\mathrm{c}}\left(\mathrm{T}-\mathrm{T}_{\mathrm{a}}\right)
$$

and a flux due to radiation:

$$
\mathrm{q}_{\mathrm{r}}=-\beta \varepsilon\left(\mathrm{T}^{4}-\mathrm{T}_{\infty}^{4}\right)
$$

In the above $T_{a}$ is the ambient temperature, $\alpha_{c}$ is the convection heat transfer coefficient, $\beta$ is the StefanBoltzmann constant, $\varepsilon$ the emissivity, and $\mathrm{T}_{\infty}$ the absorbing surface temperature. Thus, the two boundary conditions combine to give:

$$
\mathrm{q}_{\mathrm{rc}}=\mathrm{q}_{\mathrm{r}}+\mathrm{q}_{\mathrm{c}}
$$

The essential thermal boundary conditions are prescribed temperatures in the contact zones between the glass and the mould and are imposed in the finite element model by a penalty function technique, as explained in the next section.

\subsection{Boundary conditions}

As the simulation of the forming process takes place the boundary conditions must be changed whenever the material touches the mould. Initially, a contact algorithm deals with this problem by redefining the time step, so that the nodes of the mesh representing the glass do not penetrate into the mesh that represents the mould, [17]. A node achieving contact with the mould is considered to be fixed, which seems to be a reasonable assumption due 
to the sudden drop of temperature and the consequent local large increase on viscosity.

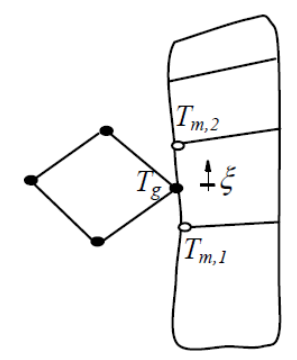

Figure 1. Thermal contact

The thermal boundary conditions must also be changed and the node temperature is constrained to be the same as the mould temperature in the point of contact. This is achieved by imposing, with a penalty function technique, the condition:

$$
\mathrm{T}_{\mathrm{g}}=\mathrm{N}_{\mathrm{m}, 1}(\zeta) \mathrm{T}_{\mathrm{m}, 1}+\mathrm{N}_{\mathrm{m}, 2}(\zeta) \mathrm{T}_{\mathrm{m}, 2}
$$

where $T_{g}$ is the temperature at the contacting node of the glass mesh, $T_{m}, 1$ and $T_{m, 2}$ are the node temperatures on the side of the mould element where contact is made, and $\mathrm{N}_{\mathrm{m}, 1}$ and $\mathrm{N}_{\mathrm{m}, 2}$ are the respective shape functions, Figure 1

\section{Numerical Modelling}

In the production of glass containers there are two ways to perform a final product, the press and blow or blow and blow operations. Glass containers are manufactured by melting raw materials and recycled glass in tank furnaces which melt the glass at an elevated temperatures. Then, the molten glass is cut into gobs of the same shape and size and sent to a high speed machines. These gobs fall into a first mould, the blank mould, and are pressed (press and blow) or blown (blow and blow) against the mould wall forming the parison. The parison in then transferred to a second and final mould where, by gravity first and then pressure (or sometimes suction), the final product is finished.

A software to simulate the production of glass containers was developed. The software is able to reproduce the blow and blow and press and blow processes allowing to simulate all the stages, since gob loading to final blow.

Initial gob shape was assumed a "spherocylinder" with an initial velocity of $6 \mathrm{~m} / \mathrm{s}$. In the blow and blow process a gob of a flint glass with $0.400 \mathrm{Kg}$ of mass was considered. The initial gob temperature was $1135^{\circ} \mathrm{C}$ and assumed as uniform. Tools temperatures considered were: for plunger and neckring a temperature of $550^{\circ} \mathrm{C}$; for the blank mould and baffle a temperature of $450^{\circ} \mathrm{C}$ and finally for blow mould a temperature of $480^{\circ} \mathrm{C}$. The air pressure used was of 2.5.

In the press and blow the same material was used. The initial temperature were taken as $1170^{\circ} \mathrm{C}$ for the gob, $550^{\circ} \mathrm{C}$ for the plunger, $420^{\circ} \mathrm{C}$ for the neckring, $450^{\circ} \mathrm{C}$ for the blank mould and baffle, $480^{\circ} \mathrm{C}$ for the blow mould. To the plunger a force of $400 \mathrm{~N}$ was applied.
A remeshing procedure is necessary when the elements become too distorted and consequently a capability to interpolate state variables (thermal and mechanical) from the old to the new mesh is necessary, allowing for a continuous process modelling.

\section{Results}

The first example refers to all stages of the blow and blow process. The figures show results for important thermomechanical stages namely shape and temperature distribution.

Figures 2 and 3 represent gob loading and settle blow. In Figure 3 can be seen the cooling effect after filling completely the neckring.

After the settle blow the plunger is removed to allow the corkage reheat in plunger zone, i.e. glass nearby the plunger will reheat and soften for better counter blow pressure effect. Figure 4 shows the end of counter blow stage. The following stages are the reheat and invert. After the counter blow the blank mould is opened and the parison is allowed to reheat before inverting into the blow mould. During this time, the parison continues its reheat or temperature equalization. Then, the parison is transferred to the blow mould.

At the rundown gravity is the only force acting in this stage, Figure 5. A cooling effect will appear when the glass contacts the baffle and is followed by the final blow.

In final blow stage inflated pressurize air forces the parison to finalize the container shape. Additionally, vacuum is also applied from the blow mould. Figure 6 represents the temperature evolution in final blow stage. It can be noted that the neckring region is cooler than the other zones. Results present uniform thickness along the container profile, with more material in the bottom and thinner thickness in the shoulder, as expected.

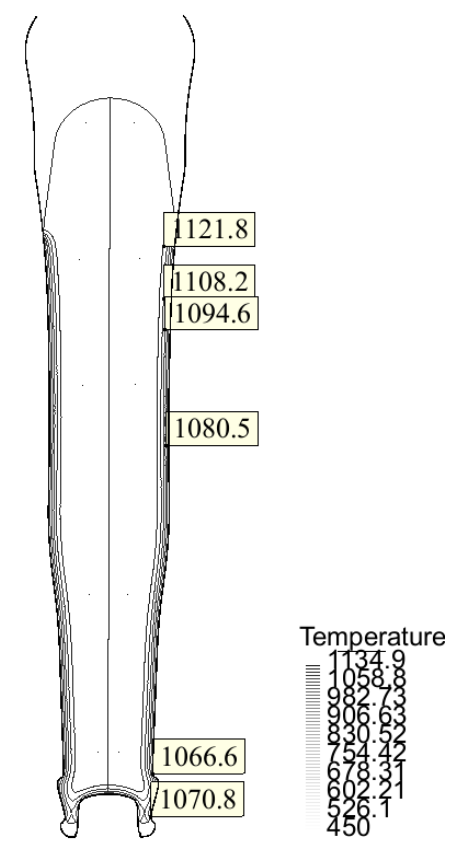

Figure 2. Gob loading in blow and blow process 


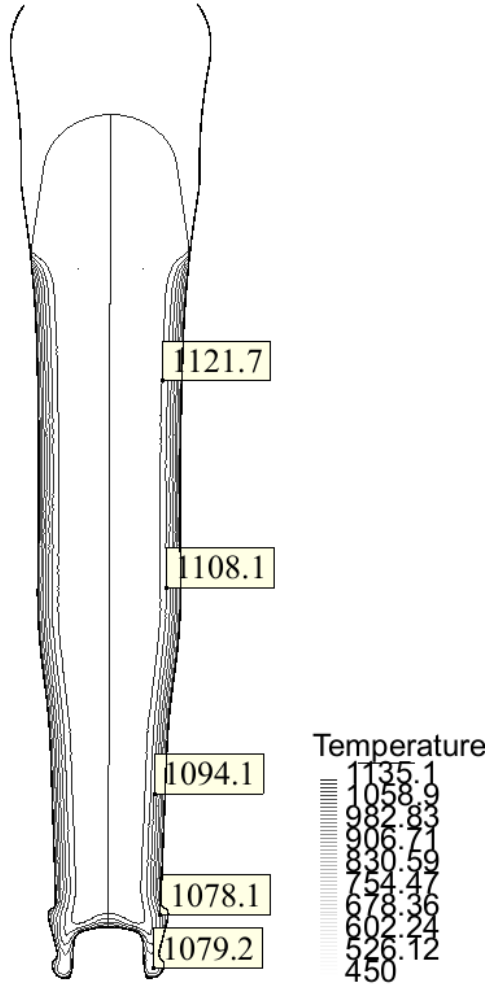

Figure 3. Settle blow in blow and blow process.

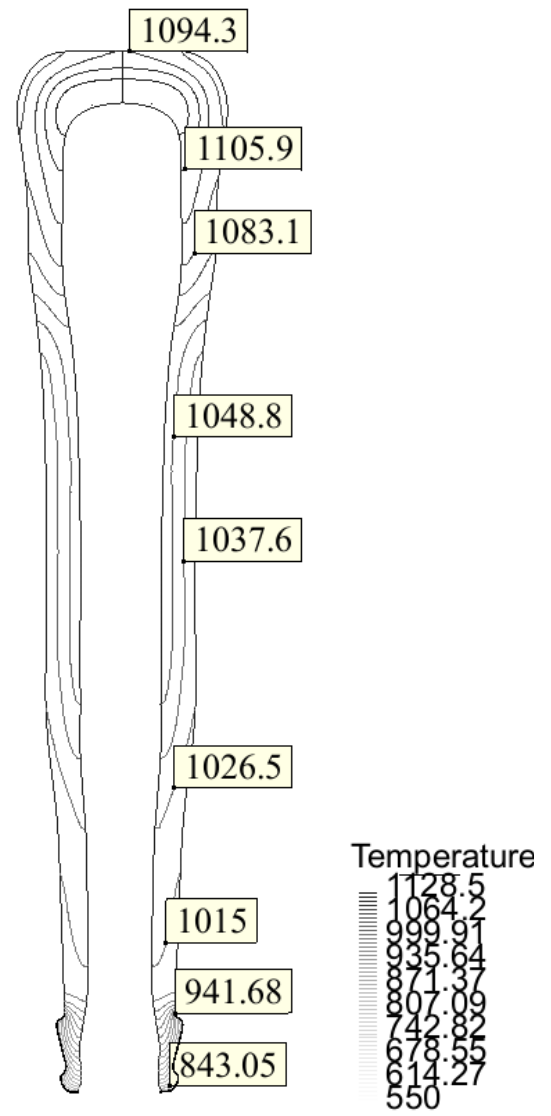

Figure 4. Counter blow in blow and blow process

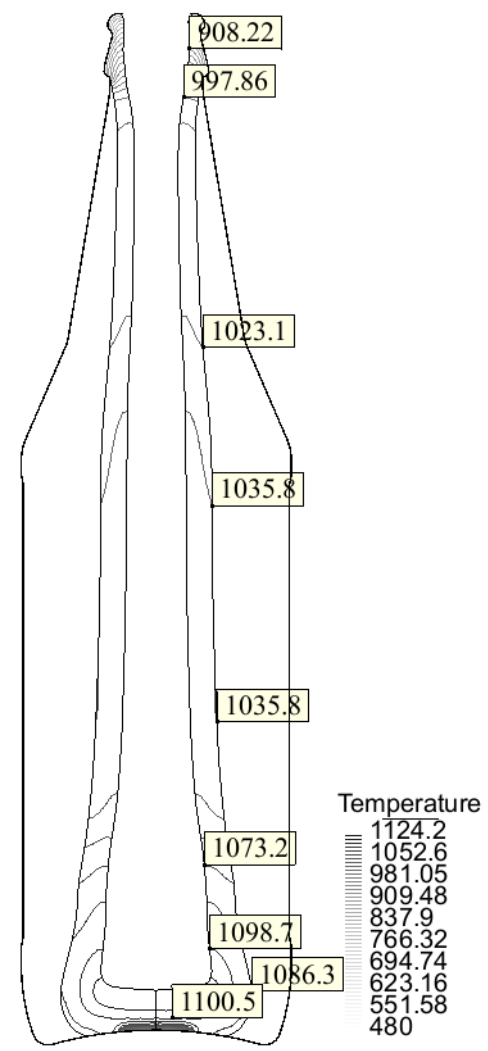

Figure 5. Rundown in blow and blow process

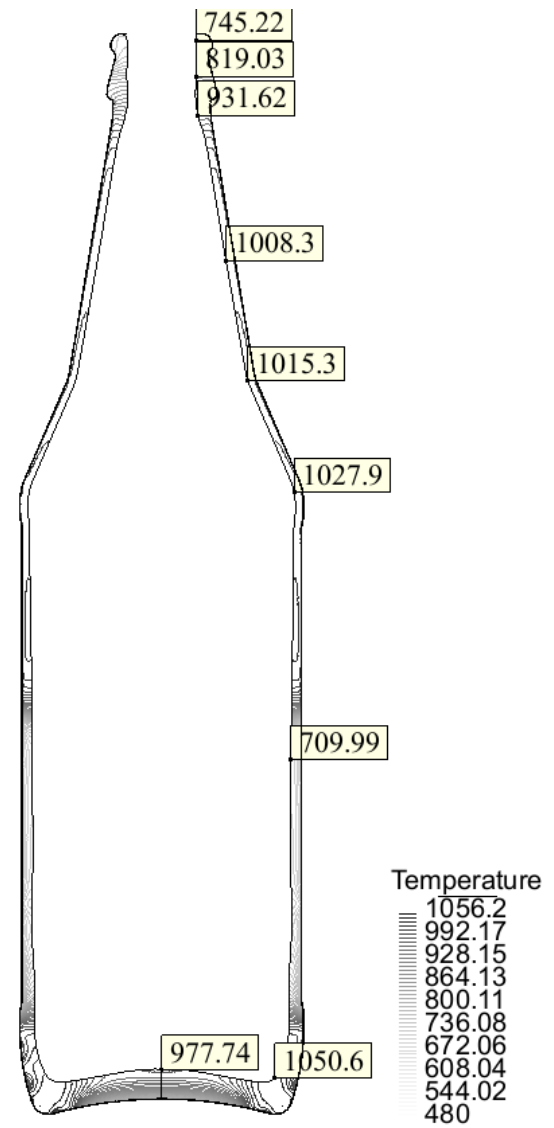

Figure 6. Final blow in blow and blow process 
The first example refers to all stages of the press and blow process. Figure 7 represents the gob loading stage, glass is dropped directly against the plunger and starts to cool. Then, the baffle is positioned on top of the blank mould and the plunger starts move towards the baffle with a prescribed force. In the last instants the glass fills the neckring zone. Figure 8 shows the final step of plunger up stage. Comparing to the similar blow and blow process, Figure 4, the glass presents a different temperature evolution in consequence to contact to the plunger. It can be noted a more 'horizontal' isothermal evolution, presenting a cooling effect from the top to the bottom while in counter blow of the blow and blow process present a 'vertical' isothermal evolution, showing the cooling effect from the mould to inside of parison, is more clear.

After plunger up stage follows the reheat and invert stages which are critical to perform a successful rundown stage. Too much cooling can result in a deficient rundown. Not enough cooling, in other hand, would have the opposite effect, i.e., excessive stretching in the wall resulting in a very thinner wall glass during the rundown. Thus, the time of invert should be in according to the desire container final shape. Figure 8 represents the rundown. As the cooling advances the bottom of the container presents a higher temperature distribution than the top, which is a result of a bigger thickness.

In Figure 10 the final blow stage is presented. Note that the neckring and the shoulder are cooler than the other zones, as expected. Also, thickness is well distributed showing a larger quantity of material at the bottom and being uniform along the wall.

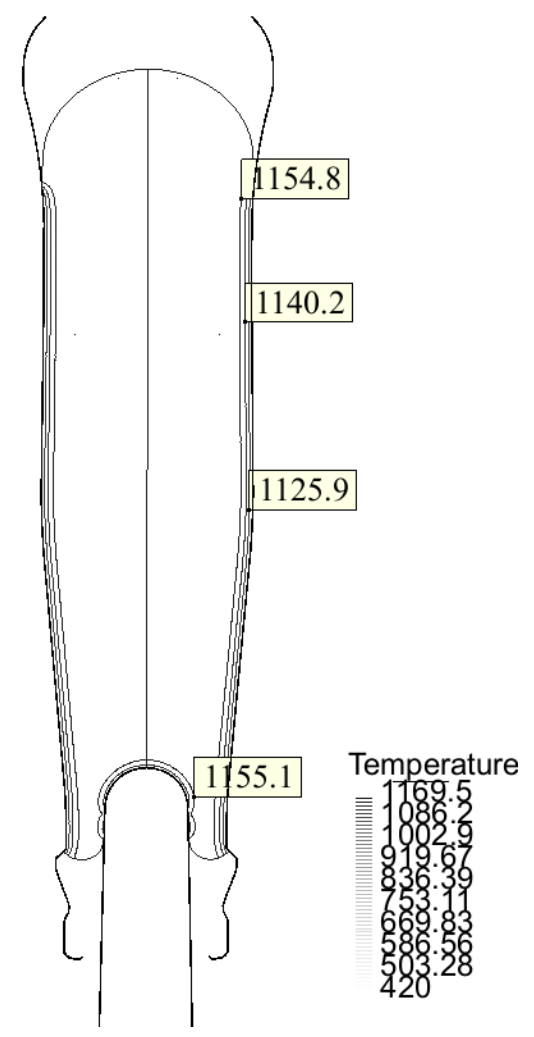

Figure 7. Gob loading in press and blow process

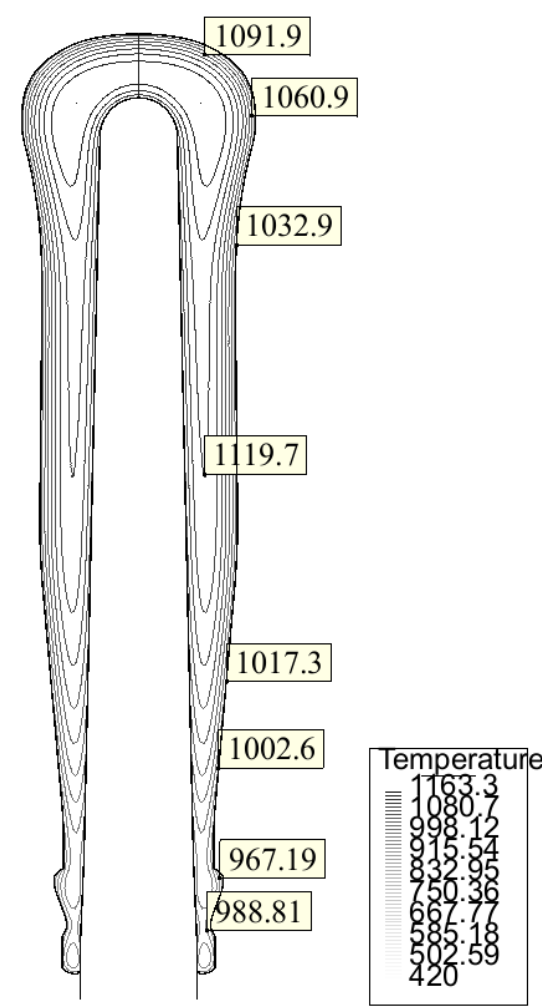

Figure 8. Plunger up in press and blow process.

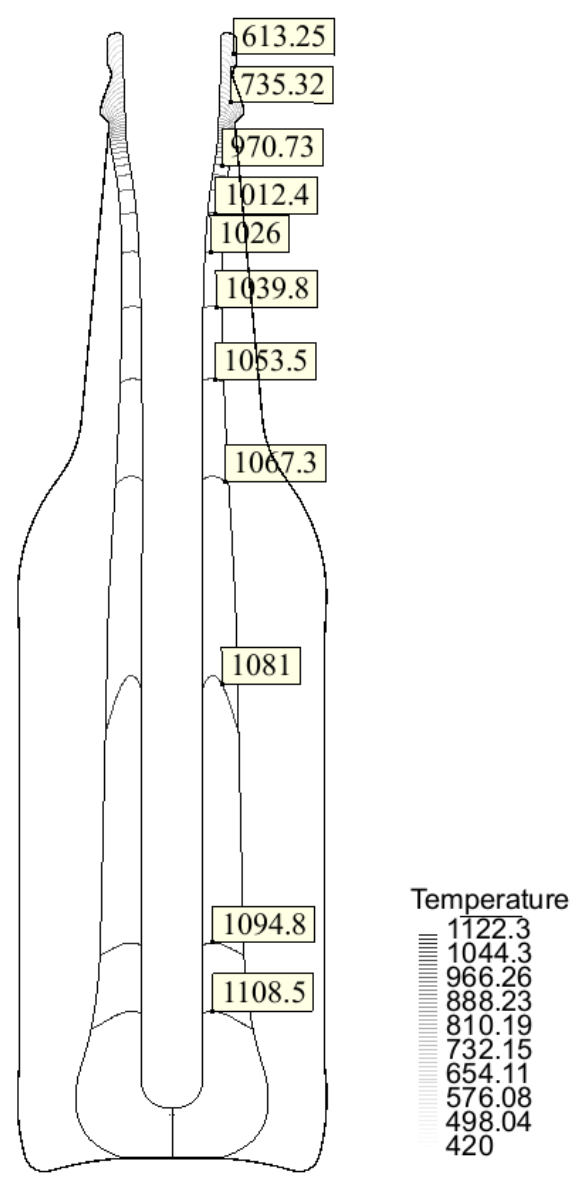

Figure 9. Rundown in press and blow process. 


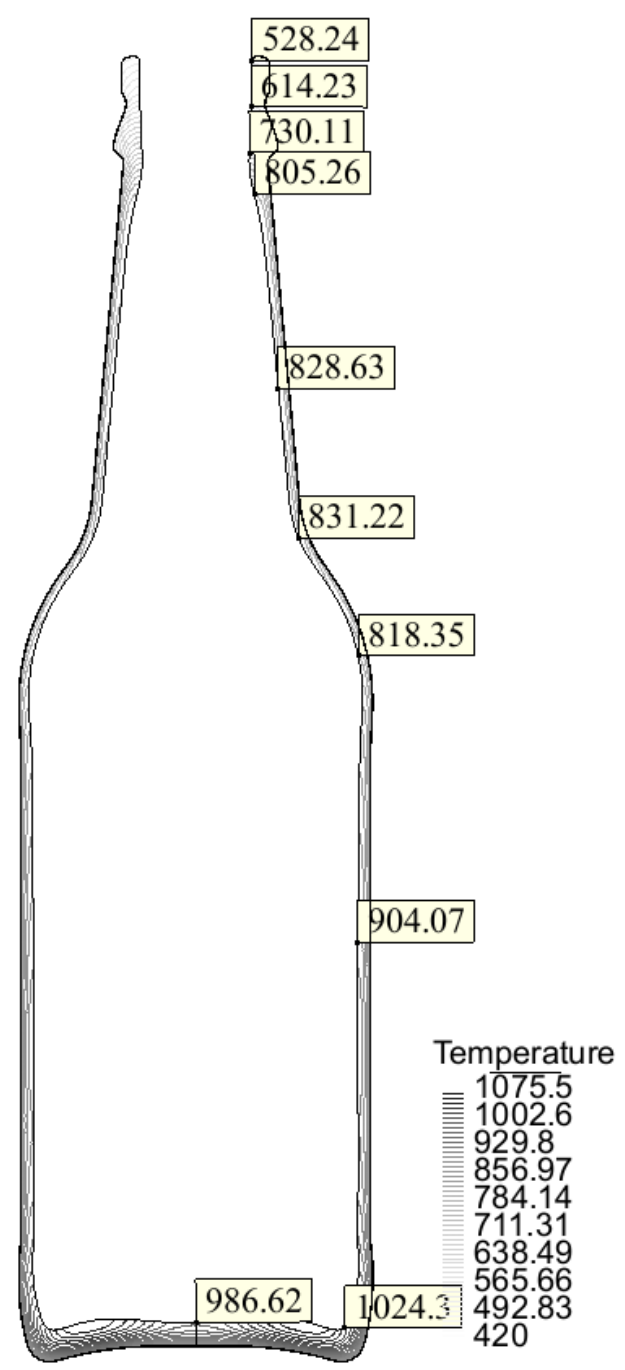

Figure 10. Final blow in press and blow process.

\section{Conclusion}

A development of numerical software for forming of glass containers has been performed. Two different glass containers have been simulated for two typical blow and blow and press and blow processes.

The main goal is to perform automatically all the stages without user handling. The software is able to efficiently choose the timestep, boundary conditions, loads, remeshing parameters and to transfer all information to a new mesh as well as all calculation to perform the simulation successfully.

The results show reliability and robustness of the developed computational tool

\section{Acknowledgements}

Authors gratefully acknowledge the funding of Project NORTE-01-0145-FEDER-000022 - SciTech - Science and Technology for Competitive and Sustainable Industries, cofinanced by Programa Operacional Regional do Norte (NORTE2020), through Fundo Europeu de Desenvolvimento Regional.

\section{References}

1. JH. Williams, DRJ. Owen, JMA. Cesar de Sa, Proceedings of the XIVth Inter. Congress on Glass, (1986).

2. JMA. César de Sá,, Engineering Computations; 3(6): 266-275, (1986)

3. K. Storck, Studies in Science and Technology. Dissertation $n^{\circ}$ 542, (1998).

4. D. Lochegnies, C. Maréchal, In: Proceedings of the $2^{\text {nd }}$ international colloquium Modelling of Glass Forming and Tempering. Presses, (2002).

5. JMA. Cesar de Sa, RM. Natal-Jorge, RPR. Cardoso, In: Proceedings of the Euromech 388 Colloqium on Modelling of Glass Forming Processes. Lez Valenciennes n ${ }^{\circ}$ 27, (1999).

6. JMA. Cesar de Sa, RM. Natal-Jorge, CMC. Silva, RPR. Cardoso, Proceedings of ECCM'99- European Conference on Computational Mechanics, (1999).

7. D . Lochegnies, P. Moreau, R. Guilbaut, Glass Technology, 46(2): 116-120, (2005).

8. C. Maréchal, P. Moreau, D. Lochegnies, Engineering with Computers, 19: 233-240, (2004).

9. Elfen GD, Glass Design Modelling Software, Rockfield Software Ltd

10. ABAQUS, Finite Element Analysis, Dassault Systèmes

11. Ansys Fluent, CFD software, ANSYS, Inc.

12. NoGRID, Flow simulation for industrial processes and operations, NOGRID GmbH

13 Babcock, C.L., Silicate glass technology methods, (John Wiley \& Sons, New York, 1977)

14 Fung, Y.C., Foundations of Solid Mechanics, (Prentice-Hall, New Jersey, USA, 1965)

15 Owen, D.R.J., Hinton, E., Finite Elements in Plasticity: Theory and Practice, (1980).

16 Fulcher, G.S.., J. Amer. Ceram. Soc., Vol 8/6, p. 339-355, (1925). 